HUILING ZHANG, Ph.D. ${ }^{1,2}$

E-mail: huilingz@126.com

${ }^{1}$ Chongqing Key Lab of Traffic System \& Safety

in Mountain Cities, No 66. Xuefu Road, Nan'an District,

Chongqing, 400074, P. R. China

2 Transportation School, Chongqing Jiaotong University

No 66. Xuefu Road, Nan'an District, Chongqing,

400074, P. R. China
Traffic Engineering

Original Scientific Paper

Submitted: 2 Nov. 2018

Accepted: 4 Oct. 2019

\title{
THRESHOLD RESEARCH ON THE ELDERLY PEDESTRIAN RATIO IN PEDESTRIAN CROSSING SPEED SETTING ON SIGNALIZED CROSSWALKS IN CHINA
}

\begin{abstract}
Inadequate consideration of the elderly people crossing demand on the signalized intersections would bring great potential safety hazards, especially the speed through the crosswalk. By observing the pedestrian walking speed at three signalized crosswalks and a relatively spacious sidewalk in Chongqing, China, this paper has obtained the walking speed values of 658 elderly people and 1,176 adults at the signalized crosswalks, as well as the walking speed parameters of 868 adults and $422 \mathrm{el}$ derly people on a relatively spacious sidewalk section. Comparing the walking speed of adults walking along the sidewalk section and on signalized crosswalks, the data show that there is no significant difference between these two site speeds. Similarly, when comparing the two site data of the elderly, it is found that their walking speed at the signalized crosswalk is significantly higher than that on the sidewalk section. That is to say, the speed setting for the old people crossing the crosswalk has not been fully considered. Subsequently, taking the elderly's walking speed as input parameter, establishing the simulation models under different proportions of the elderly and different pedestrian flows, and then gain the walking speed values of the pedestrians with different quantities and different proportion of the elderly pedestrians. With the help of the unknown breakpoint Regression method, under the setting of the elderly pedestrian speed crossing the street, the proportion threshold of the elderly crossing the street at the signalized intersection is obtained. The results show that when the proportion of the elderly is more than $15 \%$ of the pedestrians crossing the street, the pedestrian crossing speed value for the signal time is suggested to be $0.97 \mathrm{~m} / \mathrm{s}$.
\end{abstract}

\section{KEY WORDS}

pedestrian crossing speed; elderly pedestrian ratio; regression model; threshold; Vissim simulation;

\section{INTRODUCTION}

According to the United Nations forecast [1], the proportion of elderly people over the age of 60 in the world will rise from $10.0 \%$ in 2000 to $21.7 \%$ in 2050 . In recent years, the elderly population in China has also grown rapidly. According to the Chinese government statistics, until 2016, the number of elderly people over the age of 60 in China reached 220 million, accounting for $16.1 \%$ of the total [2]. Internationally, when the people of a country or a region at the age over 60 account for more than $10 \%$ of the population, or more than $7 \%$ of the total population over the age of 65 , the country or region are declared as having entered an aging society. Therefore, China has now entered an aging society, and the proportion of the elderly has gradually increased in the coming decades. The body and mind of the elderly people gradually degenerate with age, body-associated phenomena can relate to such things as manifesting poor body coordination, slow movement, significantly reduced step length and step frequency; impaired vision and hearing, with psychological phenomena such as anxiety, confusion, and vulnerability to interference. The combination of these factors make the elderly people "slower" when crossing a crosswalk. In summary, the special physical and psychological characteristics of the elderly pedestrians result in different traffic characteristics. With the gradually increasing proportion of the elderly people, the walking speed research of the elderly people has gradually attracted the attention of scholars. Dündar [3] tested that there were significant differences among different ages in Istanbul. Coffin et al. [4] analysed the speed 
of the elderly at signalized intersections, un-signalized intersections, and crosswalks, and given the design speed of the elderly pedestrian crossings at the un-signalized intersections set to $1.0 \mathrm{~m} / \mathrm{s}$, the signalized intersections should be set to $1.2 \mathrm{~m} / \mathrm{s}$. Fildes et al. [5] interviewed 1,600 elderly and young drivers and pedestrians in a city in Australia. They found that the purpose of the elderly travel mainly focused on tourism and attending meetings. Moreover, at the un-signalized intersections, there was insufficient understanding of the right of passage, and traffic awareness was insufficient as well. Bernhof et al. [6] compared the travel preferences of the elderly people and adults through a questionnaire survey. Knoblauch et al. [7] investigated the walking speed of pedestrians at different signalized intersections in various situations, and found the $15^{\text {th }}$ percentile crossing speed to be $1.25 \mathrm{~m} / \mathrm{s}$ and 0.97 $\mathrm{m} / \mathrm{s}$ for the adult and elderly pedestrians. Xiong et al. [8] obtained that the mean walking speed of the elderly was $1.04 \mathrm{~m} / \mathrm{s}$ through the conducted survey in Beijing, China. Through the setting camera, Oxley et al. [9] observed that the elderly pedestrians spend more time evaluating the traffic condition and looking at the road, and young people focus on the nearby traffic conditions. Moreover, elderly people have been easily confused in complex traffic situations that require multiple sensory judgments. Tim et al. [10] surveyed pedestrians at ten intersections to get pedestrian speed in different situations. It is proposed that when the proportion of pedestrians over the age of 65 exceeds $20 \%, 30 \%, 40 \%$, and $50 \%$ of the total pedestrians at a location, the walking speeds of 1.10, 1.07, 1.04 and $1.01 \mathrm{~m} / \mathrm{s}$, respectively, have been recommended. For intersections where almost all the pedestrians are over the age of 65 , the walking speed of $0.88 \mathrm{~m} / \mathrm{s}$ has been recommended. Through a 12-year follow-up survey, Elizabeth A. et al. [11] made a growth curve analysis to predict the walking speed change with the age increment to predict the change in walking speed with the age increase. The survey results have shown that only $10 \%$ of the elderly over 60 years of age can reach $1.2 \mathrm{~m} / \mathrm{s}$. The data from more than 2,000 pedestrians in seven countries show that the mean walking speed of the elderly was between $0.97 \mathrm{~m} / \mathrm{s}$ and $1.4 \mathrm{~m} / \mathrm{s}$, and the $15^{\text {th }}$ percentile walking speed was between $0.67 \mathrm{~m} / \mathrm{s}$ and $1.2 \mathrm{~m} / \mathrm{s}$. In Sao Paulo, Brazil, $97.8 \%$ of elderly pedestrians cross the street at a street speed of less than $1.2 \mathrm{~m} / \mathrm{s}$, and $69.7 \%$ of the elderly have a street crossing speed of more than
$0.9 \mathrm{~m} / \mathrm{s}$ [12]. In other words, if the design speed was $1.2 \mathrm{~m} / \mathrm{s}, 97.8 \%$ of the elderly would not safely cross the street within the specified time. In HCM2000 [13], it is recommended that the proportion of the elderly in the area below $20 \%$ adopts $1.22 \mathrm{~m} / \mathrm{s}$ as the design speed, and in the area where the proportion of the elderly exceeds $20 \%$, the design speed is 1.00 $\mathrm{m} / \mathrm{s}$, and if the proportion of the elderly increases by $10 \%$, the pedestrian walking design speed is reduced by $0.1 \mathrm{~m} / \mathrm{s}$. Trpkovic et al. [14] investigated the walking speed of the elderly pedestrians at ten intersections, and the $15^{\text {th }}$ percentile walking speed was $0.88 \mathrm{~m} / \mathrm{s}$. For the relationship between the proportion of the elderly pedestrians and the pedestrian crossing speed value, Milazzo et al. found the $15^{\text {th }}$ percentile walking speed when reduced by at least 0.05 from the recommended value was taken as the design speed of the elderly pedestrian crossing street, and the elderly pedestrian threshold was obtained. Through the simulation method, the studied speed value was $1.0 \mathrm{~m} / \mathrm{s}$ when the elderly pedestrian ratio was over $20 \%$ [15]. However, other related documents have not systematically analysed the threshold of the elderly pedestrian ratio when crossing the signalized crosswalk.

This paper takes over 60 -year-old pedestrians (China's 60-year-olds as the demarcation point of the elderly) as the main research objects, and analyses the elderly and adult (aged between 18 and 60) pedestrian walking speed at the signalized crosswalk with different facilities. Through the calibrated VISSIM simulation platform to analyse the walking speed at different pedestrian flows and different proportions of the elderly conditions, and using the estimating regression models with unknown breakpoints, the relationship between the proportion of the elderly people and the whole pedestrian walking speed characteristics is analysed, and the threshold of the elderly pedestrian ratio is obtained when setting the pedestrian crossing speed value and the walking values at the signalized intersections in China are recommended.

\section{METHODOLOGY AND MATERIALS}

\subsection{Data collection}

The consideration of the selected field sites should have the following features: (1) there are many elderly pedestrians at the signalized crosswalks; (2) there is a pedestrian signal and the pedestrian green time is more than $10 \mathrm{~s}$, thus being 
able to get more sample data; (3) the waiting area has enough space, and (4) the view is good for the pedestrian can see the vehicle condition and the camera can be set. Through the pilot survey and several times field observation, three signalized intersections were selected in Chongqing, China for the elderly pedestrians crossing speed collections. They are Qinglong-Nanhu intersection (Location A), Huilong-Qinglong intersection (Location B) and signalized mid-block located at Xuefu Road (Location C), shown in Figure 1.

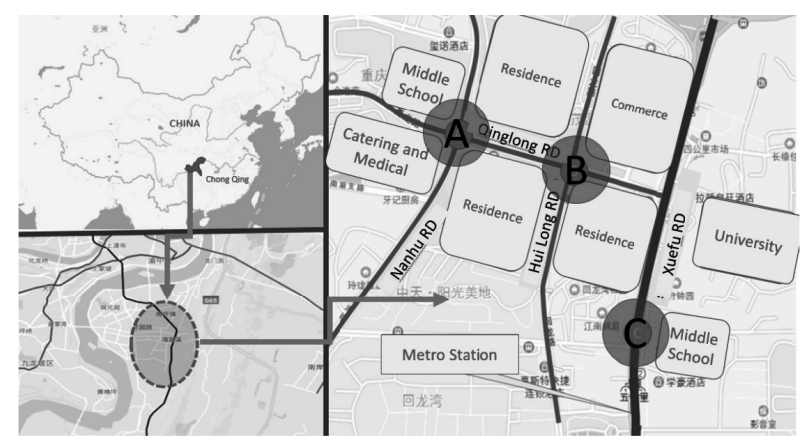

Figure 1 - Survey location map

There are many residential, catering, school, and medical facilities around the selected survey sites, which can attract a large number of people. Pedestrians frequently use crosswalks during the trip, providing a basis for data collection. The survey of the specific circumstances is shown in Table 1.

All of these intersections have pedestrian signal countdown timer, and only location $\mathrm{C}$ has a pedestrian median refuge. The width of the median refuge is $1.5 \mathrm{~m}$ of the location $\mathrm{C}$. The cross section data are shown in Figure 2.
Using an HD camera to record the pedestrian crossing process, the camera is placed in a position where the pedestrian can be completely observed. As shown in Figure 3, the record information such as the conversion of the signal colour during recording. At the same time, the camera should be avoided to attract the attention of pedestrians when being erected.

According to the above method, the data recording time was from $14^{\text {th }}$ December to $18^{\text {th }}$ December 2015 workdays, and the weather condition was good. In order to get more samples, the second sample collection time was on the $21^{\text {st }}$ March, 2017 at position $\mathrm{C}$. The crossing speed data for the elderly and the adults using video-by-frame playback was obtained. In order to increase the judgement precision of the elderly pedestrians, the observer was asked to judge the elderly pedestrians through the video, and then verify by asking the pedestrian's age; then the observer was able to have the experience to extract the data. Moreover, by visually judging the gender and age range of the pedestrians, the pedestrians who carried heavy objects, accompanied children crossing the street, cycled, and strollers were not recorded. The pedestrian crossing speed was extracted, and 2,374 pedestrian data were collected in total, including 1,716 adult pedestrians and 658 elderly pedestrians.

The sidewalk near the Ertang Metro Station of the Xuefu Avenue in Chongqing City was selected as the pedestrian free-speed collection point. The location of the site is relatively flat, the view is wide, and the pedestrian flow is moderate, and the pavement adopts $25 \times 63$ floor tiles to easily es-

Table 1 - Survey of the specific circumstances

\begin{tabular}{||l|c|c|c||}
\hline \multicolumn{1}{|c|}{ Location } & A & B & C \\
\hline \hline Countdown & Y & Y & Y \\
\hline Pedestrian median refuge & $\mathrm{N}$ & $\mathrm{N}$ & 100 \\
\hline Crosswalk signal cycle $[\mathrm{s}]$ & 90 & 100 & 19 \\
\hline Pedestrian green light $[\mathrm{s}]$ & 15 & 5 & 5 \\
\hline Pedestrian green flash time $[\mathrm{s}]$ & 5 & 17 & 24 \\
\hline Crosswalk length $[\mathrm{m}]$ & 20 & 6 & 6 \\
\hline Crosswalk width $[\mathrm{m}]$ & 6 & 708 & 60 \\
\hline One-way pedestrian traffic $[\mathrm{p} / \mathrm{h}]$ & 636 & 40 & two boards \\
\hline Vehicle speed limit $[\mathrm{km} / \mathrm{h}]$ & 40 & undivided roadway & $2,832 \mathrm{pcu} / \mathrm{h}$ one direction \\
\hline Road section & undivided roadway & $708 \mathrm{pcu} / \mathrm{h}$ one direction & \\
\hline Vehicle traffic flow & $972 \mathrm{pcu} / \mathrm{h}$ one direction & & \\
\hline
\end{tabular}




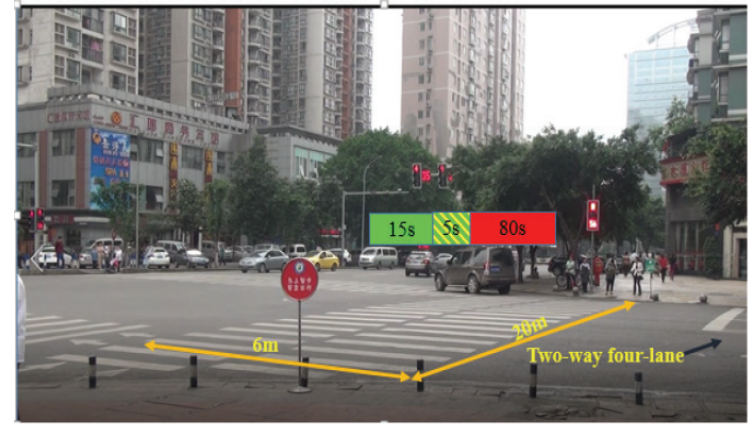

a) Location $A$

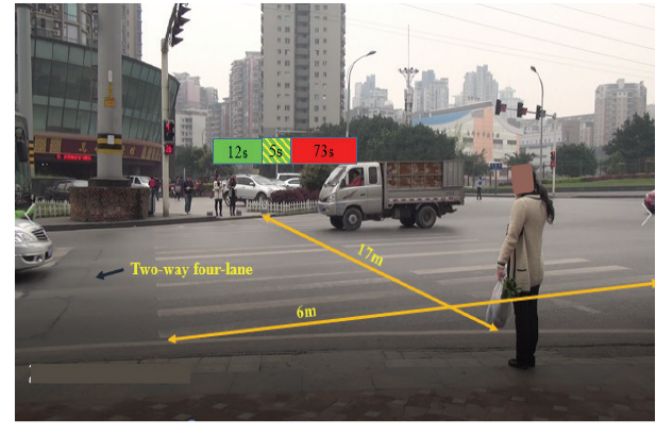

b) Location $B$

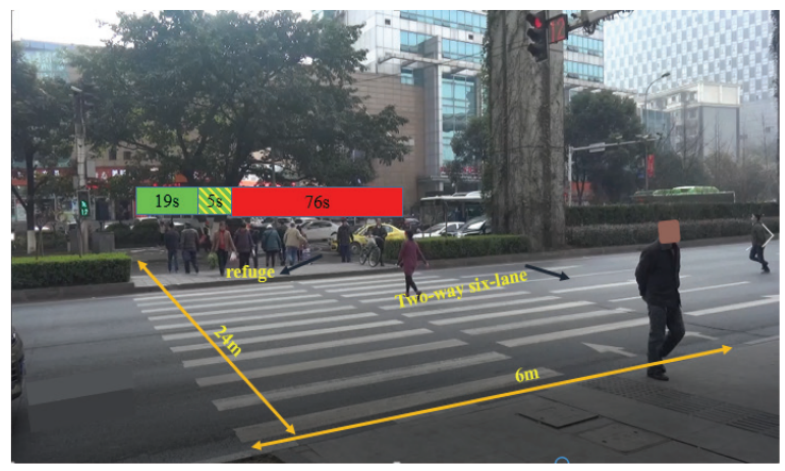

c) Location $C$

Figure 2 - The crosswalk condition data of the survey sites

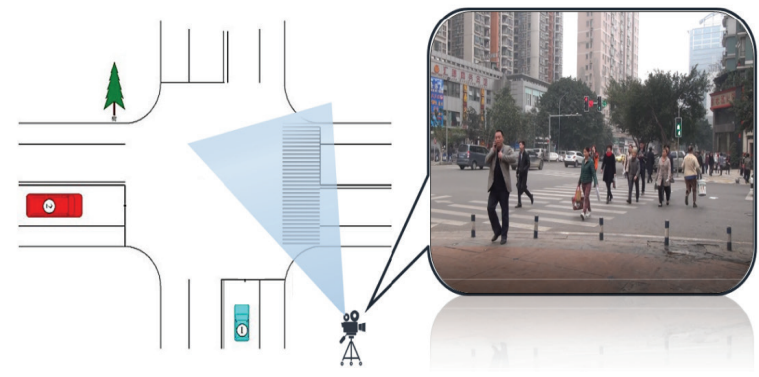

Figure 3 - Schematic diagram of data acquisition

timate the pedestrian walking distance and will not attract pedestrian attention, as shown in Figure 4. The recording of data was from $8^{\text {th }}-10^{\text {th }}$ March, 2017.

The pedestrians do not necessarily step on the set start or finish lines when walking into the observation area. When manually extracting the parameters, the pedestrians who do not step on the line in or out of the observation area are not recorded.

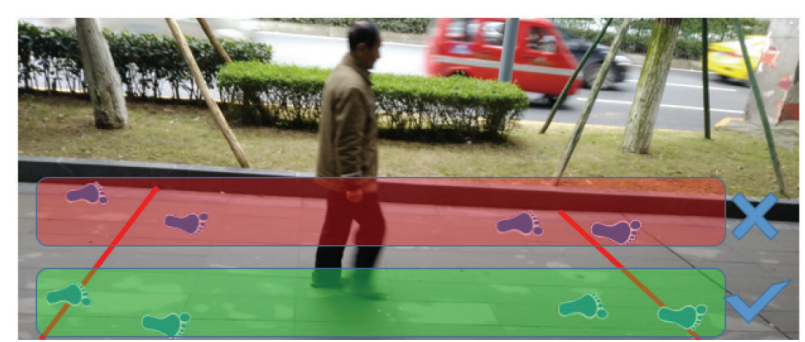

Figure 4 - Schematic diagram of sidewalk speed acquisition
The walking speed value of the pedestrian can be obtained by recording the times when the pedestrian enters and leaves the observation area, in combination with the previously determined marker length. As shown in Formula 1.

$$
v=\frac{l}{t}
$$

where $v$ is the walking speed of the pedestrian, $[\mathrm{m} / \mathrm{s}] ; l$ is the length of the observed section, $[\mathrm{m}]$; $t$ is the time difference of the pedestrian passing through the observation section, [s].

The parameters such as the step length of the pedestrian can be obtained by recording the number of steps of the pedestrian in the observation interval, and the step length can be calculated by Formula 2.

$s=\frac{l}{n}$

where $s$ is the pedestrian step length, $[\mathrm{m} / \mathrm{step}] ; l$ is the length of the measurement interval, $[\mathrm{m}] ; n$ is the number of walking steps of the pedestrian in the measurement interval, [steps].

The step frequency is calculated as shown in Formula 3.

$f=\frac{n}{t}$

where $f$ is the pedestrian step frequency, [step/s]. 


\subsection{Data analysis}

As described above, limited by the body degeneration and the long reaction time to the external environment information, the elderly pedestrian speed and other traffic features would be different with the adults. Moreover, a different traffic facility setting affects the elderly pedestrian traffic parameters. The following hypothesis has been made:

1) There are different step speeds between the elderly and the adults when crossing a signalized crosswalk;

2) There are different speeds for the elderly pedestrians in case there is a pedestrian median refuge and without it.

Statistical analysis is carried out on testing the crossing speed differences of the elderly and adult data collected above. The output results include speed average, standard deviation, extreme value, $15^{\text {th }}$ and $85^{\text {th }}$ percentile walking speed, as listed in Table 2 .

The results show that at intersection $\mathrm{A}$, the mean speed of adult pedestrians is $1.18 \mathrm{~m} / \mathrm{s}$, and the average speed of elderly pedestrians is $1.05 \mathrm{~m} / \mathrm{s}$. At intersection $\mathrm{B}$, the mean speed is $1.23 \mathrm{~m} / \mathrm{s}$, and the mean speed of elderly pedestrians is $1.06 \mathrm{~m} / \mathrm{s}$. At intersection $\mathrm{C}$, the mean speed of adult pedestrians is $1.23 \mathrm{~m} / \mathrm{s}$, and the mean speed of elderly pedestrians is $1.11 \mathrm{~m} / \mathrm{s}$. Overall, the mean speed of adult pedestrians is $1.22 \mathrm{~m} / \mathrm{s}$, and the mean speed of elderly pedestrians is $1.08 \mathrm{~m} / \mathrm{s}$.

The pedestrian speed on the sidewalk is calculated, too. The data are provided in Table 3.

The results show that the mean walking speed of adult pedestrians is $1.21 \mathrm{~m} / \mathrm{s}$, the step length is 0.69 $\mathrm{m}$, and the step frequency is $1.80 \mathrm{steps} / \mathrm{s}$. And the mean walking speed of elderly pedestrians is 1.02 $\mathrm{m} / \mathrm{s}$, the step length is $0.62 \mathrm{~m}$, and the step frequency is $1.66 \mathrm{step} / \mathrm{s}$. The speed, step length and step frequency of the elderly when walking freely on the road are significantly smaller than those of the adults $(p<0.05)$. For pedestrians as a whole, the average speed of adults crossing the street $(1.22 \mathrm{~m} / \mathrm{s})$ is close to the walking speed of the road $(1.21 \mathrm{~m} / \mathrm{s})$. The average speed of the elderly crossing the street is $1.08 \mathrm{~m} / \mathrm{s}$, which is significantly higher than the walking speed of the road section $1.02 \mathrm{~m} / \mathrm{s}(p<0.05)$.

For the pedestrian crossing speed data of the above three signalized crosswalks, the walking speeds of the elderly and the adults are separately calculated, described in Figure 5.

As shown in Figure 5, the $15^{\text {th }}$ percentile crossing speed of the adults and the elderly at the signalized crosswalk is $1.00 \mathrm{~m} / \mathrm{s}$ and $0.97 \mathrm{~m} / \mathrm{s}$, respectively, and the difference is $0.03 \mathrm{~m} / \mathrm{s}$; the $50^{\text {th }}$ percentile crossing speed is $1.18 \mathrm{~m} / \mathrm{s}$ and $1.08 \mathrm{~m} / \mathrm{s}$, respective-

Table 2 - Pedestrians walking speed at a signalized crosswalk

\begin{tabular}{||c|c|c|c|c|c|c|c|c||}
\hline \multirow{2}{*}{ Position } & $\begin{array}{c}\text { Pedestrian } \\
\text { type }\end{array}$ & $\begin{array}{c}\text { Number } \\
\text { of records }\end{array}$ & $\begin{array}{c}\text { Mean } \\
\text { speed } \\
{[\mathrm{m} / \mathrm{s}]}\end{array}$ & $\mathrm{SD}$ & $\begin{array}{c}\text { Minimum } \\
{[\mathrm{m} / \mathrm{s}]}\end{array}$ & $\begin{array}{c}\text { Maximum } \\
{[\mathrm{m} / \mathrm{s}]}\end{array}$ & $\begin{array}{c}15^{\text {th }} \text { percentile } \\
\text { walking speed } \\
{[\mathrm{m} / \mathrm{s}]}\end{array}$ & $\begin{array}{c}85^{\text {th }} \text { percentile } \\
\text { walking speed } \\
{[\mathrm{m} / \mathrm{s}]}\end{array}$ \\
\hline \hline \multirow{2}{*}{$\mathrm{A}$} & Adults & 394 & 1.18 & 0.19 & 0.77 & 2.64 & 0.97 & 1.32 \\
\cline { 2 - 10 } & Elderly & 200 & 1.05 & 0.11 & 0.77 & 1.50 & 0.95 & 1.15 \\
\hline \multirow{2}{*}{$\mathrm{B}$} & Adults & 400 & 1.23 & 0.20 & 0.78 & 2.64 & 1.00 & 1.29 \\
\cline { 2 - 10 } & Elderly & 150 & 1.06 & 0.09 & 0.88 & 1.41 & 0.96 & 1.14 \\
\hline \multirow{2}{*}{$\mathrm{C}$} & Adults & 922 & 1.23 & 0.19 & 0.81 & 2.64 & 1.04 & 1.32 \\
\cline { 2 - 10 } & Elderly & 308 & 1.11 & 0.11 & 0.80 & 1.46 & 1.00 & 1.22 \\
\hline \multicolumn{2}{|c|}{ Adults } & 1,716 & 1.22 & 0.19 & 0.77 & 2.64 & 1.00 & 1.32 \\
\hline \multicolumn{2}{|c|}{ Elderly } & 658 & 1.08 & 0.11 & 0.77 & 1.5 & 0.97 & 1.19 \\
\hline
\end{tabular}

Table 3 -Pedestrian sidewalk section data statistics

\begin{tabular}{||l|c|c|c|c|c|c|c|c||}
\hline \multirow{2}{*}{ Speed $[\mathrm{m} / \mathrm{s}]$} & Type & $N$ & $\begin{array}{c}\text { Mean } \\
\text { speed }\end{array}$ & SD & Minima & Maxima & $\begin{array}{c}15^{\text {th }} \text { percentile } \\
\text { speed }\end{array}$ & $\begin{array}{c}85^{\text {th }} \text { percentile } \\
\text { speed }\end{array}$ \\
\hline \hline \multirow{2}{*}{ Step length $[\mathrm{m}]$} & Adults & 868 & 1.21 & 0.20 & 0.80 & 2.00 & 1.09 & 1.33 \\
\cline { 2 - 10 } & Elders & 422 & 1.02 & 0.16 & 0.76 & 1.30 & 0.76 & 1.18 \\
\hline \multirow{2}{*}{ Step frequency [m/step] } & Adults & 868 & 0.69 & 0.07 & 0.52 & 0.86 & 0.63 & 0.75 \\
\cline { 2 - 10 } & Elders & 422 & 0.62 & 0.08 & 0.45 & 0.68 & 0.50 & 0.68 \\
\cline { 2 - 10 } & Adults & 868 & 1.80 & 0.18 & 1.36 & 2.33 & 1.60 & 2.00 \\
\hline
\end{tabular}




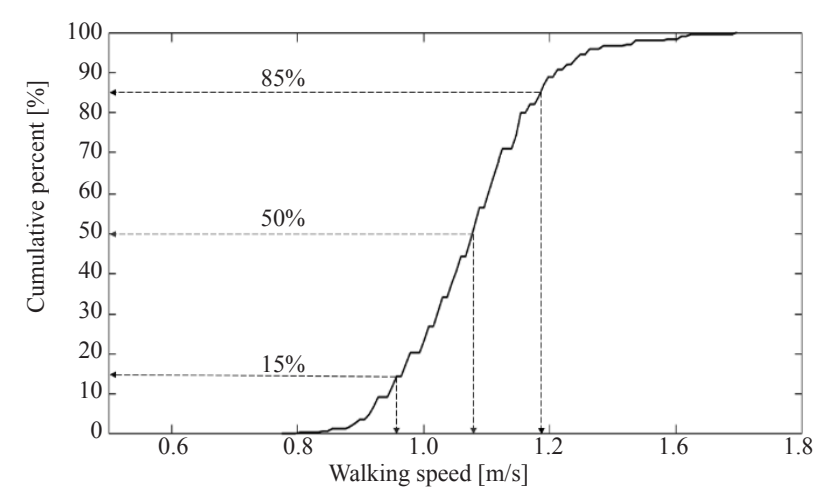

a) The elderly

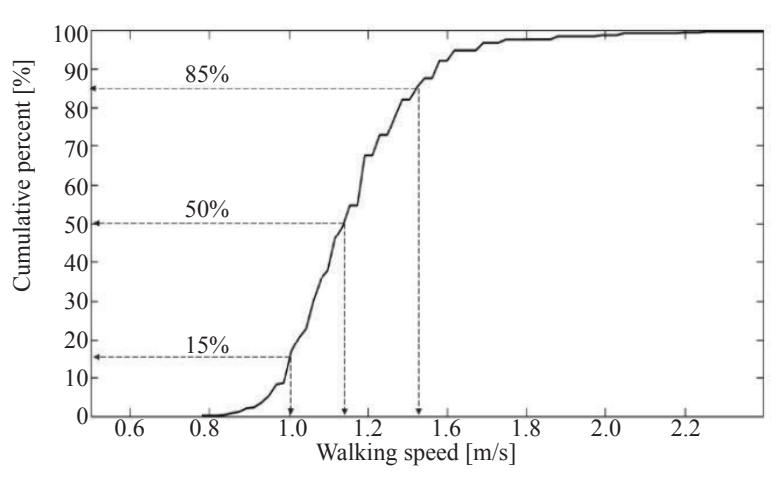

b) The adults

Figure 5 - Cumulative frequency of pedestrian walking speed in adults and seniors

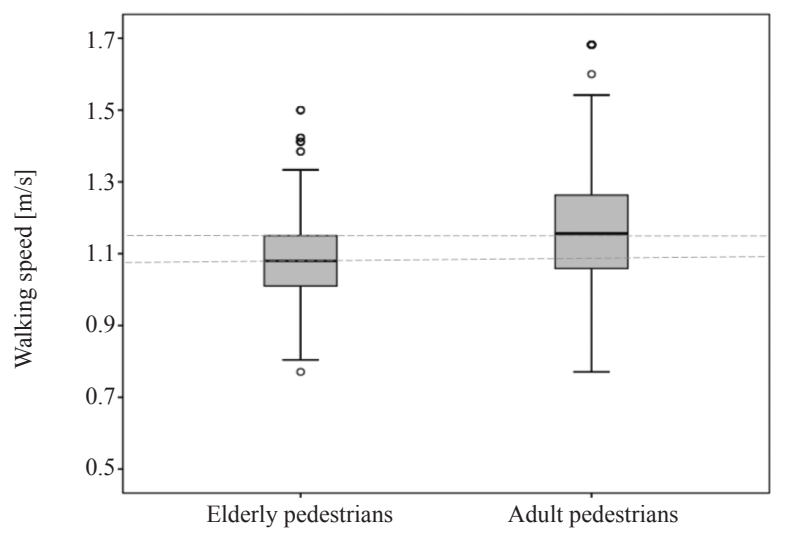

Figure 6-Pedestrian walking speed box at the signalized crosswalks

ly, and the difference is $0.10 \mathrm{~m} / \mathrm{s}$; the $85^{\text {th }}$ percentile crossing speeds are $1.32 \mathrm{~m} / \mathrm{s}$ and $1.19 \mathrm{~m} / \mathrm{s}$, respectively, and the difference is $0.13 \mathrm{~m} / \mathrm{s}$.

To further explore the differences between the adults and the elderly, a boxplot analysis of their crossing speed has been provided in Figure 6 .

As shown in Figure 6, the adult speed distribution is on the upper side, the box is relatively long, and some points are larger than $1.5 \mathrm{~m} / \mathrm{s}$, indicating that the adult speed distribution is relatively scattered, and some adults pass the crosswalk at a much faster speed. At the signalized crosswalks, on the contrary, the speed distribution of the elderly is lower, the box is shorter, the data are more concentrated, and the abnormally large points are fewer, but some abnormally small speed values appear. The results are in line with the characteristics of each type of a pedestrian.

\subsection{Thresholds for the proportion and speed of elderly people}

Vissim simulation experiment

As analysed above, there is a significant difference in the walking speed between the elderly and the adults. The walking speed, step frequency, and step length of the elderly are significantly lower than those of the adults. The pedestrian crossing speed will be affected when pedestrians are mixed in different proportions of the elderlies. Considering the Viswalk module in Vissim simulation software, the pedestrian traffic behaviour of different pedestrians can be described in detail, which is suitable for analysing different proportions of elderly people, including crossing speed characteristics. So, Viswalk is chosen for the construction of the simulation platform. The specific scene is constructed as follows: a crosswalk with a length of $20 \mathrm{~m}$ and a width of $6 \mathrm{~m}$ is established in Vissim, and the pedestrian signal period is set to $60 \mathrm{~s}$, where the red light duration is $38 \mathrm{~s}$, the green light duration is $6 \mathrm{~s}$, and the green flash time is $16 \mathrm{~s}$. Considering the normal standard of China [16] and the HCM2000 value [13], the experiment sets the pedestrian flow at three LOSs, explained in Table 4.

At the same LOS, the proportion of the elderly is gradually increased from $5 \%$ to $80 \%$, and the growth size is $5 \%$. Three different random speed numbers are set for simulation under the same scale. The screenshot of the simulation model interfaces are shown in Figure 7.

Table 4 - Pedestrian traffic at different LOS

\begin{tabular}{||c|c|c|l||}
\hline LOS & Volume $[\mathrm{p} / \mathrm{m} \cdot \mathrm{min}]$ & Space occupied $\left[\mathrm{m}^{2} / \mathrm{p}\right]$ & \multicolumn{1}{c||}{ Feeling } \\
\hline \hline A & $\leq 30$ & $>2.3$ & $\begin{array}{l}\text { The action is completely free and almost unaffected by the people } \\
\text { around you }\end{array}$ \\
\hline B & $30-55$ & $0.9-2.3$ & The action is limited; severely inconvenient when reversed and crossed \\
\hline
\end{tabular}




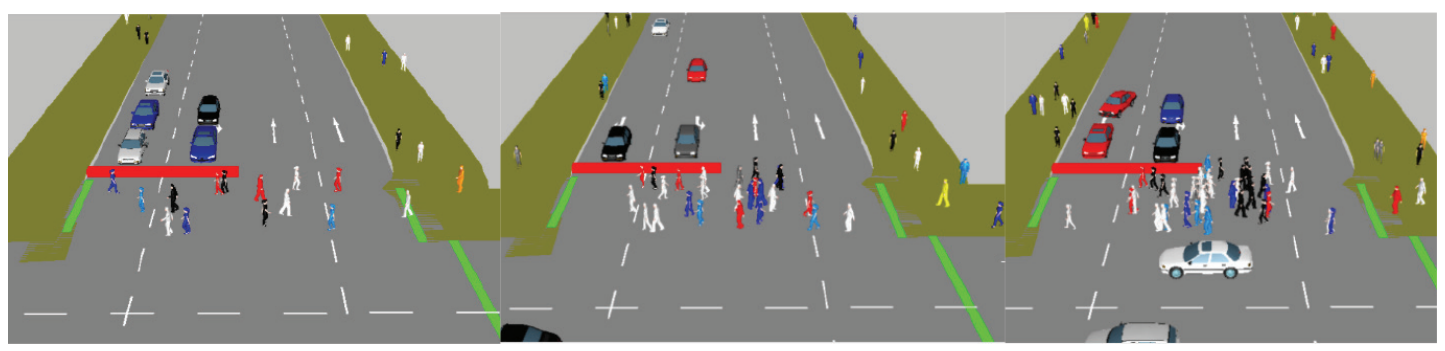

a) Simulation diagram at $\operatorname{LOS} A$

b) Simulation diagram at LOS B

c) Simulation diagram at LOS C

Figure 7 - Schematic diagram of simulation in different densities

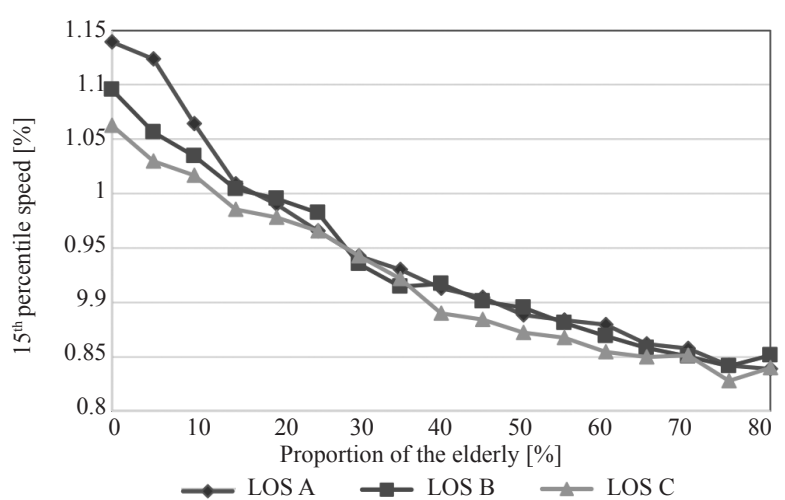

Figure 8 - The relationship between pedestrian $15^{\text {th }}$ percentile speed and the proportion of the elderly

According to the literature analysis, $15^{\text {th }}$ percentile walking speed is often used as a reference when determining the pedestrian crossing design speed, and the $15^{\text {th }}$ percentile walking speed has great research significance. Therefore, the subsequent analysis is based on the pedestrian $15^{\text {th }}$ percentile speed. Through the simulation platform, the relationship between the proportion of different elderly people and the $15^{\text {th }}$ percentile speed of pedestrian crossing under different LOS conditions is obtained (Figure 8).

Figure 8 shows that as the proportion of elderly people increases, the $15^{\text {th }}$ percentile speed of pedestrians gradually decreases, which can be explained in two aspects. Firstly, the speed of some elderly people is naturally reduced and the overall speed is lowered. Secondly, when the faster pedestrians behind the street team want to go beyond the slower elderly, they must move laterally to avoid collisions, which will increase the delay and slow down the

Table 5 -Pedestrian $15^{\text {th }}$ percentile speed curve fitting

\begin{tabular}{||l|c|c|c||}
\hline & \multicolumn{3}{|c||}{ Decisive factor $\left(R^{2}\right)$} \\
\hline \hline Model & LOS A & LOS B & LOS C \\
\hline Linear & 0.8946 & 0.8954 & 0.9254 \\
\hline Exponent & 0.919 & 0.9192 & 0.9598 \\
\hline Logarithm & 0.9809 & 0.9971 & 0.9359 \\
\hline Binomial & 0.9822 & 0.9754 & 0.9872 \\
\hline
\end{tabular}

speed. When the proportion of the elderly reaches a certain LOS, the $15^{\text {th }}$ percentile speed of the pedestrian will be abrupt, which will be discussed next. In order to meet the conditions of the regression model for estimating the unknown inflection point, first ensure that the data are non-linear. Curve fitting is performed on the $15^{\text {th }}$ percentile of the three horizontal descendants using different models (Table 5).

The fitting results show that the results of non-linear fitting are always better than linear fitting, so the non-linear relationship between the $15^{\text {th }}$ percentile speed of pedestrians and the proportion of the elderly is considered to be obvious. A regression model that estimates the unknown inflection point can be used for the analysis.

\section{Threshold analysis for elderly people}

For the $15^{\text {th }}$ percentile speed of pedestrians in different proportions of the elderly has a non-linear relationship; this analysis selects a regression model based on the unknown inflection point to study. The model uses a kind of method of estimating a polyline model that simplifies the problem into a linear framework [17]. This method is very simple in concept, but it is also very versatile and suitable for many situations; it is easy to consider the multiple parameters and it is only used to estimate the starting value of the inflection point. So, the regression model is used to analyse the threshold of the elderly people ratio.

\section{RESULTS}

In this paper, the $15^{\text {th }}$ percentile speed of pedestrians is used as the dependent variable, and the proportion of the elderly is used as an independent variable. The scatter data obtained by the above model are fitted by the 1stopt software, and the value of the inflection point is estimated. The model fitting result is represented in Figure 9. 


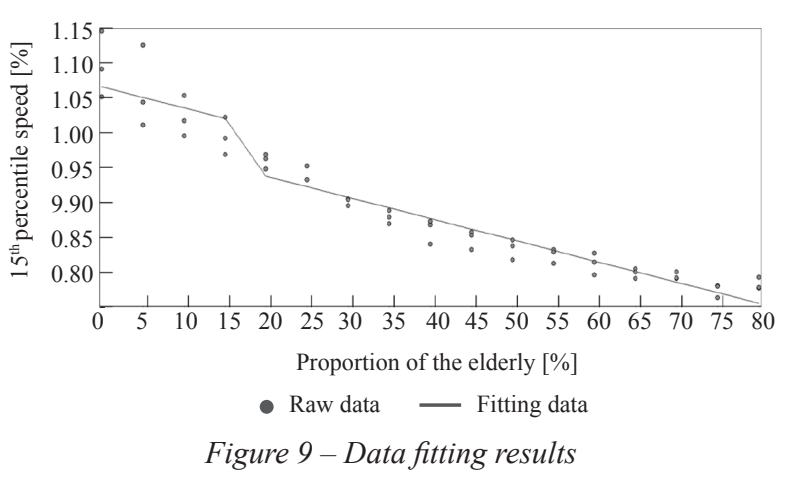

Considering that the three sets of data are obtained under different flows of LOS, if the inflection point is judged separately for the data at a certain LOS, the generality of the conclusion is poor. Therefore, considering the three sets of data, the quasi-Newton method (BFGS) is one of the most effective methods for solving non-linear optimization problems [18, 19], using the quasi-Newton method (BFGS) + general global optimization method to estimate the convergence of the model, after several iterations, finally reaching the convergence criterion (Table 6).

Table 6 - Fitting results evaluation parameters

\begin{tabular}{|c|c|c|c|c||}
\hline RMSE & SSE & $R$ & Chi-square & $F$-statistic \\
\hline \hline 0.02 & 0.02 & 0.97 & 0.00 & 810.50 \\
\hline
\end{tabular}

\section{DISCUSSION}

The mean-variance is 0.02 in the evaluation parameters in Table 6, indicating that the data are concentrated; the sum of squares of the residuals is 0.02 , showing that the fitted curve is very close to the scattered data; the correlation coefficient is 0.97 , indicating that there is strong correlation between the proportion of the elderly and the pedestrian walking speed; and a large $F$ value indicates a high degree of accuracy. The results show that the fitting piecewise linear function can reflect the relationship between the $15^{\text {th }}$ percentile speed of pedestrian crossing and the proportion of the elderly. The estimated values of the inflection point are $\varphi_{1}=0.15$ and $\varphi_{2}=0.20$. That is, when the proportion of the elderly reaches $15 \%$, the first inflection point appears. At this time, the $15^{\text {th }}$ percentile speed of the pedestrians shows a "bridging" decline, which shows that the speed of pedestrians is greatly affected. After reaching $20 \%$, the elderly gradually recover to be stable. In combination with the previous analysis, in order to ensure that the elderly can safely cross the crosswalk during the green time, it is recommended to use the $15^{\text {th }}$ percentile speed $(0.97 \mathrm{~m} / \mathrm{s})$ of the elderly as the pedestrian crossing design speed in areas where the proportion of the elderly exceeds $15 \%$. In addition, with reference to relevant research, it is recommended that the proportion of the elderly exceeds $15 \%$, and for every $10 \%$ increase, the value of the crossing speed is reduced by $0.1 \mathrm{~m} / \mathrm{s}$ [12]. The speed value researched in the paper is the same as the Knoblauch [7] results, but lower than the values given in HCM and by Coffin et al $[4,8,10,13]$, and higher than the values given by Diaz and Trpkovic $[12,14]$. About the elderly pedestrian ratio that setting the speed is lower than the $20 \%$ provided by the researchers $[10,13,15]$.

\section{CONCLUSION}

With the aggravation of China's aging society, the traffic participation ratio of the elderly people will become higher and higher. How to adjust the transportation facilities fitness in the aging society has become an urgent need to be solved. Especially the speed value setting at the signalized crosswalk, it would make the pedestrian safer for the intersection if the value is properly chosen. In this paper, the data of the elderly and adult walking at the section of sidewalk and the three signalized crosswalks are obtained through field investigation. The relationship between the proportion of the elderly and the pedestrian crossing speed has been analysed. The main conclusions are summarized as follows:

1) The crossing speed, step frequency and step length of the elderly pedestrians are lower than those of the adults on the sidewalk, and the crossing speed of the elderly people at the signalized crosswalk is significantly higher than the walking speed on the sidewalk, while the adult speed data are not much different on the sidewalk and the signalized crosswalk.

2) Comparing the conditions of cases with and without the pedestrian median refuge, it can be concluded that the elderly pedestrians prefer the low speed when there is the median refuge.

3) At the signalized crosswalks, when the proportion of the elderly exceeds $15 \%$, it is recommended to use $0.97 \mathrm{~m} / \mathrm{s}$ as the walking design speed of pedestrian crossing, which allows the elderly to cross the street at a relatively comfortable speed, thereby improving the safety of the intersection.

4) Combining the traffic characteristics of the elderly and the adult pedestrians walking on the signalized crosswalk in Chongqing, China, this paper 
needs further detailed analyses of the setting of the pedestrian crossing speed at the signalized crosswalk when the proportion of the elderly pedestrians exceeds $25 \%$ and the pedestrian flow increases, which is also the next step in the research.

\section{ACKNOWLEDGEMENT}

The authors would like to thank the Natural Science Foundation of China (51508061), the Science and Technology Research Program of Chongqing Municipal Education Commission (KJQN201800727), and the open foundation of Chongqing Key Lab of Traffic System \& Safety in Mountain Cities (2018TSSMC03).

\section{张惠玲，葛鹏}

\section{中国信号交叉口老年人过街比例阈值在行人过 街速度设置方面的研究 \\ 摘要}

老年人在信号交叉口的过街需求考虑不足会带来 较大的安全隐患, 尤其过街速度。论文对中国重庆 市 3 个信号控制斑马线和一个较为宽敞的路段行人步 行速度等参数进行了人工观测, 得到了658名老年 人和 1176 名成年人在信号控制地点的步行速度值; 同时, 得到了 868 名成年人和 422 名老年人在较为宽 敞路段的步行速度等参数。将成年人和老年人在路 段及信号控制斑马线的速度进行对比, 数据显示成 年人在路段和信号控制斑马线的行走速度差异不 大，而老年人在信号控制的地点步行速度显著高于 路段, 即老年人过街速度设置考虑不足。随后将老 年人在路段的步行速度作为输入，建立不同比例老 年人及不同行人流量下的仿真模型，得到了不同人 流量下不同老年人混合比例下整体行人的步行速度 值。借助未知拐点回归模型, 得到了信号控制斑马 线老年人过街速度设置时的老年人过街比例阈值。 结果表明：老年人的过街比例超过 $15 \%$ 的情况下， 建议信号灯设置的行人过街速度为 $0.97 \mathrm{~m} / \mathrm{s}$ 。

\section{关键词}

行人过街速度; 老年人比例; 回归模型; 阈值; Vissim仿真

\section{REFERENCES}

[1] Melorose J, Perroy R, Careas S. World population prospects. United Nations. 2015;1(6042): 587-92.

[2] National Bureau of Statistics of the People's Republic of China. China statistical yearbook; 2018. Available from: http://www.stats.gov.cn/tjsj/
[3] Dündar S. Analysis of pedestrian crossing speed - the case of Istanbul. Proceedings of the Institution of Civil Engineers - Municipal Engineer. 2017;170(1): 29-37.

[4] Coffin A, Morrall J. Walking Speeds of Elderly Pedestrians at Crosswalks. Transportation Research Record. 1995;1487: 63-67.

[5] Fildes BN, Lee SJ, Kenny D, Foddy W. Survey of older road users: Behavioural and travel issue. Monash University Accident Research Centre, Report No. 57, 1994.

[6] Bernhoft IM, Carstensen G. Preferences and behavior of pedestrians and cyclists by age and gender. Transportation Research Part F. 2008;11(2): 83-95.

[7] Knoblauch RL, Ietrucha MTP, Nitzburg M. Field Studies of Pedestrian Walking Speed and Start-Up Time. Transportation Research Record, Journal of the Transportation Research Board. 1996;1538(1): 27-38.

[8] Xiong H, Lv J, Jiang X, et al. Pedestrian Walking Speed, Step Size, and Step Frequency from the Perspective of Gender and Age: Case Study in Beijing, China. Transportation Research Board Meeting; 2007.

[9] Oxley J, Fildes B, Ihsen E, Day R, Charlton J. Investigation of road crossing behaviour of older pedestrians. Monash University Accident Research Centre, Report No. 81, 1995.

[10] Gates T, Noyce D, Bill A, Van Ee N. Recommended Walking Speeds for Timing of Pedestrian Clearance Intervals Based on Characteristics of the Pedestrian Population. Transportation Research Record, Journal of the Transportation Research Board. 1982;1: 38-47.

[11] Webb EA, Bell S, Lacey RE, Abell JG. Crossing the road in time: Inequalities in older people's walking speeds. Journal of Transport \& Health. 2017;5: 77-83.

[12] Diaz AJA. Analysis of pedestrian walking speed for traffic engineering design and operations. University of Manitoba, 2008.

[13] Transportation Research Board. Highway Capacity Manual 2000. Washington D. C.: TRB, National Research Council; 2000.

[14] Trpkovic A, Milenkovic M, Vujanic M, et al. The Crossing Speed of Elderly Pedestrians. Promet - Traffic\& Transportation. 2017;29(2): 175-183.

[15] Milazzo II JS, Rouphail NM, Hummer JE, Allen DP. Quality of Service for Uninterrupted-Flow Pedestrian Facilities in Highway Capacity Manual 20001. Transportation Research Record. 1999;1678: 18-24.

[16] Industry standard of the People's Republic of China (CJJ37-2012). Code for design of urban road engineering, 2016.

[17] Muggeo VM. Estimating regression models with unknown break-points. Statistics in Medicine. 2003;22(19): 3055-3071.

[18] Shanno DF. Conditioning of quasi-Newton methods for function minimization. Mathematics of Computation. 1970;24(111): 647-656.

[19] Yuan YX. A Modified BFGS Algorithm for Unconstrained Optimization. IMA Journal of Numerical Analysis. 1991;11(3): 325-332. 